Original

\title{
Effect of preliminary irradiation on depth of cure and hardness of a veneering composite
}

\author{
Yoshifumi Matsumoto ${ }^{1)}$, Mika Furuchi ${ }^{2,3)}$, Hiroyasu Koizumi ${ }^{2,3)}$ \\ and Hideo Matsumura ${ }^{2,3)}$ \\ ${ }^{1)}$ Division of Applied Oral Sciences, Nihon University Graduate School of Dentistry, Tokyo, Japan \\ ${ }^{2)}$ Department of Fixed Prosthodontics, Nihon University School of Dentistry, Tokyo, Japan \\ ${ }^{3)}$ Division of Advanced Dental Treatment, Dental Research Center, Nihon University School of Dentistry, \\ Tokyo, Japan
}

(Received 28 November and accepted 14 December 2009)

\begin{abstract}
This study evaluated the effect of preliminary irradiation on the depth of cure and Knoop hardness of a veneering composite. The composite was filled into a mold, and irradiated with different irradiation duration or irradiance. After removing the mold, the depth of cure was measured, and the Knoop hardness number at each depth was determined and statistically analyzed using Mann-Whitney $U$ test. Depth of cure of the composite polymerized by the Sublite $S$ unit with a distance of $15 \mathrm{~cm}$ for 30 or $60 \mathrm{~s}$ was less than $2.0 \mathrm{~mm}$. The Knoop hardness number of the group polymerized by the Hyper LII unit without preliminary irradiation and the group polymerized by the Sublite $S$ unit with a distance of $3 \mathrm{~cm}$ was higher than that of the group polymerized by the Sublite $S$ unit for $90 \mathrm{~s}$ or the group polymerized by the Solidilite unit, respectively, even though the depth of cure for these four groups was higher than $2 \mathrm{~mm}$. Preliminary irradiation with long duration and low irradiance caused a low degree of polymerization, which is probably effective in enhancing the bond strength between veneering composite and cast framework. (J Oral Sci 52, 71-75, 2010)
\end{abstract}

Correspondence to Dr. Mika Furuchi, Department of Fixed Prosthodontics, Nihon University School of Dentistry, 1-8-13 Kanda-Surugadai, Chiyoda-ku, Tokyo 101-8310, Japan

Tel: +81-3-3219-8145

Fax: +81-3-3219-8351

E-mail: nemoto@dent.nihon-u.ac.jp
Keywords: veneering composite; depth of cure; Knoop hardness; curing units; irradiance.

\section{Introduction}

Indirect composites designed for veneering cast frameworks are polymerized using laboratory photo curing units. The application of high intensity photo curing units, e.g., metal halide lamps, is effective for improving physical properties (1-3), wear resistance (4,5), and monomer conversion (4) of indirect composites. However, a previous study indicated that the preliminary irradiation with short duration or high intensity reduced the bond strength between the veneering composite and alloy (6). The authors speculated that the difference in bond strength was derived from the difference in contraction stress during polymerization or in mechanical strength. It has been also reported that the initial high irradiation to restorative composites reduced the bond strength $(7,8)$ or cavity wall adaptation $(9,10)$, and induced polymerization shrinkage $(11,12)$ or contraction stress $(13-15)$. Therefore, soft-start polymerization, which is an irradiation mode with a preliminary low irradiance, is recommended for restorative composites $(7,9,11,16)$. However, little is known about the influence of preliminary irradiation on the degree of polymerization of the indirect composite, or the influence of the degree of polymerization on the bond strength. Thus, the influence of preliminary irradiation with different duration and irradiance on the depth of cure and Knoop hardness was investigated in this study. 
Table 1 Laboratory photo curing units assessed

\begin{tabular}{lccc}
\hline Material / Trade name & Abbreviation & Manufacturer & Light source \\
\hline Intermediate photo curing unit & SU & & \\
Sublite S & Shofu Inc., Kyoto, Japan & Halogen lamp $150 \mathrm{~W} \times 1$ \\
Photo curing unit for final polymerization & & \\
Solidilite & SO & Shofu Inc. & Halogen lamp 150 W $\times 4$ \\
Hyper LIl & HY & Toho Dental Products Co., Ltd, Saitama, Japan & Metal halide lamp 150 W $\times 2$ \\
\hline
\end{tabular}

Table 2 Indirect composites assessed

\begin{tabular}{lccl}
\hline Material / Trade name & Manufacturer & Lot number & Composition \\
\hline Indirect composite & & \\
Solidex body (A3) & Shofu Inc. & 100874 & Zirconium silicate $78 w t \%$ (inorganic filler loading: $52 \mathrm{wt} \%$ ), \\
& & UDMA, photo initiator \\
Solidex opaque (A3) & Shofu Inc. & 070928 & Silica, HEMA, UDMA \\
\hline
\end{tabular}

UDMA: Dimethacryloyloxyethyl 2,2,4-(or 2,4,4-) trimethylhexamethylene diurethane; HEMA: 2-hydroxyethyl methacrylate

Table 3 Irradiation mode with different curing unit, duration, and distance

\begin{tabular}{lcccc}
\hline Code & Curing unit & $\begin{array}{c}\text { Duration } \\
(\mathrm{s})\end{array}$ & $\begin{array}{c}\text { Distance } \\
(\mathrm{cm})\end{array}$ & $\begin{array}{c}\text { Irradiance } \\
\left(\mu \mathrm{W} / \mathrm{cm}^{2}\right)\end{array}$ \\
\hline HY-9-90 & Hyper LII & 90 & 9 & 5034 \\
SU-15-30 & Sublite S & 30 & 15 & 725 \\
SU-15-60 & Sublite S & 60 & 15 & 725 \\
SU-15-90 & Sublite S & 90 & 15 & 725 \\
SU-3-60 & Sublite S & 60 & 3 & 1867 \\
SO-9-60 & Solidilite & 60 & 9 & 719 \\
\hline
\end{tabular}

Irradiance: Total amount of the spectral irradiance between $400-500 \mathrm{~nm}$ indicated in the previous study (6).

\section{Materials and Methods}

Three laboratory photo curing units employed in this study are shown in Table 1. The Sublite S unit is used for preliminary curing and is equipped with a halogen lamp. Composite material is held in the hands, and the distance between the lamp and material is estimated to be 3 to 15 $\mathrm{cm}$ from the structure, although the manufacturer of the Sublite $\mathrm{S}$ unit does not recommend a specific distance. The Solidilite unit and the Hyper LII unit are box form laboratory photo curing units for final polymerization. The light source of the Solidilite unit is four halogen lamps, whereas that of the Hyper LII unit is two metal halide lamps. An indirect composite material (Solidex, Shofu Inc., Kyoto, Japan) was selected as a veneering material (Table 2).

A polytetrafluoroethylene (PTFE) mold with a diameter of $10 \mathrm{~mm}$ and a thickness of $2 \mathrm{~mm}$ was set on a glass plate. The opaque composite was brushed onto the glass plate and polymerized by the Solidilite unit for $180 \mathrm{~s}$. The body composite was slightly overfilled into the mold. The strip and glass plate were set on the top surface of the composite and pressed to remove the excess composite. The composite was irradiated with different irradiation duration or irradiance (Table 3). The summation of irradiance between 400 and $500 \mathrm{~nm}$ of each mode was calculated with the spectral irradiance reported in the previous study (6). Immediately after removing the mold, the depth of cure was determined, therefore, the uncured material was scraped away with a plastic spatula according to ISO 4049. The thickness of the remaining material was measured with a digital micrometer (MDC-SB, Mitutoyo Corp., Kawasaki, Japan) 5 times and the mean length was calculated. 
If no composite could be removed because of the hardness (more than $2 \mathrm{~mm}$ ), the specimen was assessed using the Knoop hardness test. A disc specimen was sectioned longitudinally passing through the center with a slow speed diamond saw (Isomet, Buehler, Lake Bluff, IL, USA) under water cooling. The top and a sectional surface were ground with a \#2000 silicon-carbide abrasive paper and polished with felt and a $0.25 \mu \mathrm{m}$ diamond paste. The Knoop hardness number was determined at the center of the top surface (top) and from $0.2 \mathrm{~mm}$ to $1.8 \mathrm{~mm}$ in depth from the top surface in increments of $0.2 \mathrm{~mm}$ on the longitudinal surface using a universal indenter (HMV, Shimadzu Corp., Kyoto, Japan) under a 50 g loading for $30 \mathrm{~s}$

For depth of cure or Knoop hardness measurements, five specimens were assessed for each irradiation duration or irradiance. The median and mean Knoop hardness number of five specimens was calculated for each depth, and Mann-Whitney's $U$-test was used for statistical analysis.

\section{Results}

The mean depth of cure results are shown in Table 4. Depth of cure of the composite polymerized by the Sublite $\mathrm{S}$ unit with the distance of $15 \mathrm{~cm}$ for 30 or $60 \mathrm{~s}$ was less than $2.0 \mathrm{~mm}$. On the other hand, depth of cure for the HY9-90, SU-15-90, SU-3-60, and SO-9-60 groups was more than $2.0 \mathrm{~mm}$. Regarding the irradiation duration, longer duration produced greater depth of cure.
Knoop hardness number results are shown in Table 5. An increment in depth caused smaller Knoop hardness number. SU-15-90 and HY-9-90, as well as SU-3-60 and SO-9-60 were compared to evaluate the effect of the irradiance in the previous study, and exhibited a significant difference in bond strength (6). Since the homogeneity of variance between SU-15-90 and HY-9-90 groups and between SU-3-60 and SO-9-60 groups were not observed using the Levene test, Mann-Whitney $U$-test was used to compare the two groups with the value of statistical significance at the 0.05 level. Compared to SU-15-90 group, HY-9-90 group revealed higher Knoop hardness number at each depth. Knoop hardness number of the SU-3-60 group was significantly higher than SO-9-60 at

Table 4 Influence of preliminary irradiation modes on depth of cure

\begin{tabular}{lc}
\hline Code & $\begin{array}{c}\text { Depth of cure } \\
(\mathrm{mm})\end{array}$ \\
\hline HY-9-90 & $>2.00$ \\
SU-15-30 & 1.14 \\
SU-15-60 & 1.70 \\
SU-15-90 & $>2.00$ \\
SU-3-60 & $>2.00$ \\
SO-9-60 & $>2.00$ \\
\hline
\end{tabular}

$>2.00$ : No composite could be removed with a spatula.

Table 5 Influence of preliminary irradiation mode on Knoop hardness number for each depth

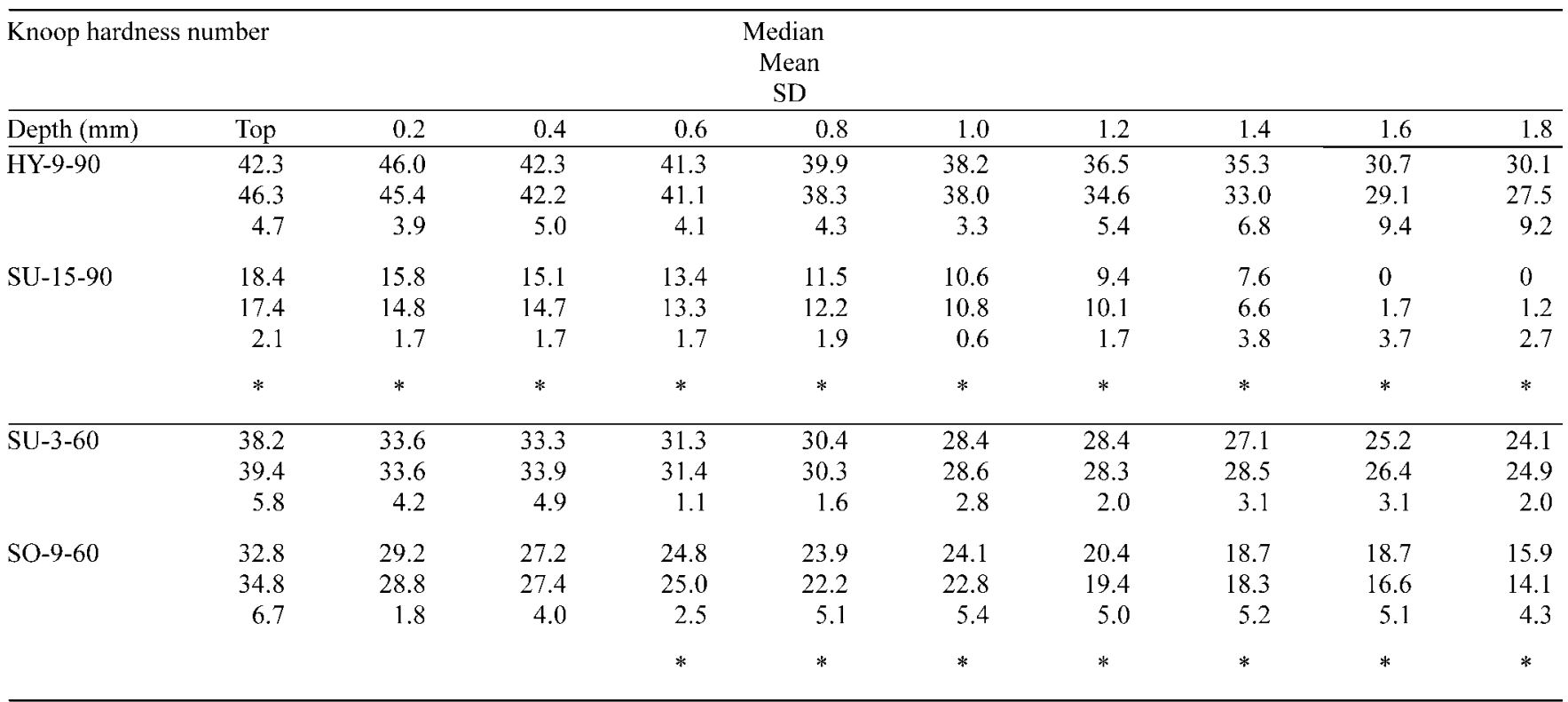

SD: Standard deviation

*: Significant difference $(P<0.05)$ 
$0.6 \mathrm{~mm}$ depth or deeper, whereas no significant differences between these two groups were observed from the top to $0.4 \mathrm{~mm}$ depth.

\section{Discussion}

The effect of preliminary irradiation on bond strength between composite and alloy was investigated in a previous study which revealed that preliminary irradiation with long duration or low intensity caused high bond strength between composite and alloy (6). Thus, in this study the influence of the preliminary curing with different irradiation durations or irradiances on degree of polymerization was investigated using depth of cure and Knoop hardness.

The depth of cure of the SU-15-30 or -60 group was less than $2 \mathrm{~mm}$, whereas there was no uncured material on the bottom of the SU-15-90. This indicates that the composite of the SU-15-30 or -60 group at the interface between composite and alloy was irradiated by the high intensity curing unit, without sufficient curing during the preliminary irradiation. A higher depth of cure was observed with an increase of the irradiation duration by the Sublite $\mathrm{S}$ unit with a distance of $15 \mathrm{~cm}$. Researchers have investigated the influence of irradiation duration on the depth of cure and found that the longer irradiation was effective for higher depth of cure $(1,17,18)$. These results agree with the current results.

The bottom of the HY-9-90, SU-15-90, SU-3-60, and SO-9-60 groups could not be removed with the spatula since it was sufficiently hard. Compared to the HY-9-90 group, the SU-15-90 group indicated a statistically lower Knoop hardness number at each depth. The bond strength of the SU-15-90 group (12.4 MPa) was significantly higher compared to the HY-9-90 group (8.3 MPa), while the irradiance of the Sublite $\mathrm{S}$ unit with a distance of $15 \mathrm{~cm}$ was found to be lower than the Hyper LII unit (6). Similarly, the Knoop hardness number of the SO-9-60 group was significantly lower compared to that of the SU-3-60 group at the depth of $0.6 \mathrm{~mm}$ or deeper. The bond strength of the SO-9-60 group (11.4 MPa), of which the irradiance was low, was significantly higher than that of the SU-3-60 group (8.7 MPa) (6). These results indicate that the low degree of polymerization at the composite-alloy interface caused by low irradiance of the preliminary irradiation was effective in enhancing the bond strength between composite and alloy. The reason for the low bond strength of the HY9-90 and SU-3-60 groups is thought to be contraction stress or polymerization shrinkage, which are caused by the rapid polymerization reaction resulting from the high intensity curing unit as a preliminary irradiation. Many studies have investigated the influence of intensity of preliminary irradiation on the adaptation or the contraction stress. The high irradiance of a preliminary irradiation produces less cavity wall adaptation $(9,10)$ or higher contraction stress (13-15). However, restorative and indirect composites differ from each other in the composition of composite, existence of the opaque layer, and the distance from the light source. Therefore, the effect of preliminary irradiation on the degree of polymerization of veneering composite was investigated in this study. Tanoue et al. also investigated the influence of the duration of the preliminary polymerization on the bond strength between indirect composite and gold alloy, and found that a longer intermediate irradiation enhanced bond strength (19). These results agree with the current observations.

Veneering composite for cast frameworks requires high physical properties, in addition to the high bond strength to alloy. A high intensity curing unit is effective for improving physical properties (2-5). The combination of a preliminary irradiation with long and low irradiance and a final polymerization with high intensity could provide good properties to veneered cast restorations.

Within the limitations of this study, it was concluded that preliminary irradiation with long duration and low irradiance provided a low degree of polymerization, which seems to be effective in enhancing the bond strength between veneering composite and alloy.

\section{Acknowledgments}

This work was supported in part by Special Research Grants for the Development of Distinctive Education from the Promotion and Mutual Aid Corporation for Private Schools of Japan (2009), and Sato Fund, Nihon University School of Dentistry (2009).

\section{References}

1. Tanoue N, Matsumura H, Atsuta M (1998) Curing depth of a composite veneering material polymerized with seven different laboratory photo-curing units. J Oral Rehabil 25, 199-203.

2. Koizumi H, Satsukawa H, Tanoue N, Ogino T, Nishiyama M, Matsumura H (2005) Effect of metal halide light source on hardness, water sorption and solubility of indirect composite material. J Oral Sci 47, 165-169.

3. Murakami M (2009) Surface properties of an indirect composite polymerized with five laboratory light polymerization systems. J Oral Sci 51, 215-221.

4. Freiberg RS, Ferracane JL (1998) Evaluation of cure, properties and wear resistance of Artglass dental composite. Am J Dent 11, 214-218.

5. Tanoue N, Matsumura H, Atsuta M (2000) Analysis of composite type and different sources of 
polymerization light on in vitro toothbrush/dentifrice abrasion resistance. J Dent 28, 355-359.

6. Matsumoto Y, Furuchi M, Oshima A, Tanoue N, Koizumi H, Matsumura H (2009) Effect of preliminary irradiation on the bond strength between a veneering composite and alloy. Dent Mater J (in press)

7. Santos AJ, Sarmento CF, Abuabara A, Aguiar FH, Lovadino JR (2006) Step-cure polymerization: effect of initial light intensity on resin/dentin bond strength in class I cavities. Oper Dent 31, 324-331.

8. Dall'Magro E, Sinhoreti MA, Correr AB, CorrerSobrinho L, Consani S, Puppin-Rontani RM (2007) Effect of different initial light intensity by the softstart photoactivation on the bond strength and Knoop hardness of a dental composite. Braz Dent J 18, 107112.

9. Yoshikawa T, Burrow MF, Tagami J (2001) A light curing method for improving marginal sealing and cavity wall adaptation of resin composite restorations. Dent Mater 17, 359-366.

10. Uno S, Tanaka T, Natsuizaka A, Abo T (2003) Effect of slow-curing on cavity wall adaptation using a new intensity-changeable light source. Dent Mater 19, 147-152.

11. Dennison JB, Yaman P, Seir R, Hamilton JC (2000) Effect of variable light intensity on composite shrinkage. J Prosthet Dent 84, 499-505.

12. Hofmann N, Denner W, Hugo B, Klaiber B (2003) The influence of plasma arc vs. halogen standard or soft-start irradiation on polymerization shrinkage kinetics of polymer matrix composites. J Dent 31, 383-393.

13. Ernst CP, Kürschner R, Rippin G, Willershausen B (2000) Stress reduction in resin-based composites cured with a two-step light-curing unit. Am J Dent 13, 69-72.

14. Lim BS, Ferracane JL, Sakaguchi RL, Condon JR (2002) Reduction of polymerization contraction stress for dental composites by two-step lightactivation. Dent Mater 18, 436-444.

15. Lu H, Stansbury JW, Bowman CN (2005) Impact of curing protocol on conversion and shrinkage stress. J Dent Res 84, 822-826.

16. Watts DC, al Hindi A (1999) Intrinsic 'soft-start' polymerisation shrinkage-kinetics in an acrylatebased resin-composite. Dent Mater 15, 39-45.

17. Rueggeberg FA, Caughman WF, Curtis JW Jr, Davis HC (1993) Factors affecting cure at depths within light-activated resin composites. Am J Dent 6, 9195.

18. Baharav H, Abraham D, Cardash HS, Helft M (1998) Effect of exposure time on the depth of polymerization of a visible light-cured composite resin. J Oral Rehabil 15, 167-172.

19. Tanoue N, Shimoe S, Atsuta M, Matsumura H (2005) Application of a preliminary light-curing unit for enhanced bonding between a gold alloy and veneering materials. Am J Dent 18, 82-86. 